\title{
Evaluation of a fracture indicator dependent on the normalized third invariant of the deviatoric stress tensor and equivalent plastic strain.
}

\author{
Leonel L. Delgado Morales* and Lucival Malcher ${ }^{\dagger}$ \\ *Austral University of Chile, General Lagos 2086, Miraflores Campus, Valdivia, Chile, \\ leonel.delgado@uach.cl \\ ${ }^{\dagger}$ University of Brasília, Campus Darcy Ribeiro, Brasília-DF-Brazil \\ malcher@unb.br
}

\begin{abstract}
The prediction of the point and the location of the fracture in ductile materials has been the motivation for several authors in recent times since from these predictions it is possible to design mechanisms that offer high reliability and structural safety. Due to the limitations of conventional models in predicting displacement to fracture, as well as the levels of reaction forces, it is necessary to consider variables when modeling in order to capture important effects on the elastoplastic behavior of materials. This work presents a new fracture indicator, which incorporates the effects of the normalized third invariant of the deviatoric stress tensor and the equivalent plastic strain, in its formulation, The proposed indicator is also coupled with the post-processing step of the Gao's constitutive model. The tests are applied to specimens manufactured from the AISI 4340 alloy in two heat treatment states. In order to compare the behavior of the material under different ductility conditions, numerical tests are performed for different stress states. The new fracture indicator presents satisfactory results when observing the forecast of the displacement in the fracture and the levels of reaction force, for the evaluated specimens used in the study. The use of this new fracture indicator can be an efficient alternative in the prediction of failures in metallic materials, with different levels of ductility, submitted to the tensile conditions, simple shear, and combined shear/tensile.
\end{abstract}

\section{REFERENCES}

[1] L. Malcher, L. L. D. Morales, V. A. M. Rodrigues, V. R. M. Silva, L. M. Araújo, G.V Ferreira. Experimental program and numerical assessment for determination of stress triaxiality and $\mathrm{J} 3$ effects on AA6101-T4. Theoretical and Applied Fracture Mechanics, https://doi.org/10.1016/j.tafmec.2020.102476 (2020)

[2] L. Malcher, F. M. Andrade Pires, J. M. A. César De Sá, An assessment of isotropic constitutive models for ductile fracture under high and low stress triaxiality. International Journal of Plasticity, v. 30-31, p. 81-115 (2012).

[2] J. V. S. Cavalheiro, L. Malcher. Assessment of third invariant elasto-plastic models: Mathematical aspects, numerical strategies and comparative results. Finite Elements in Analysis and Design, 5169 (2017). 